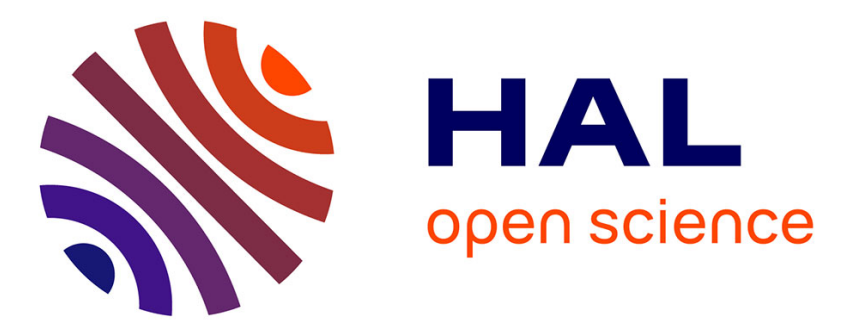

\title{
Concomitant effects of light and temperature diel variations on the growth rate and lipid production of Dunaliella salina
}

Hubert Bonnefond, N. Moelants, Amélie Talec, Olivier Bernard, A. Sciandra

\section{- To cite this version:}

Hubert Bonnefond, N. Moelants, Amélie Talec, Olivier Bernard, A. Sciandra. Concomitant effects of light and temperature diel variations on the growth rate and lipid production of Dunaliella salina. Algal Research - Biomass, Biofuels and Bioproducts, 2016, 14, pp.72-78. 10.1016/j.algal.2015.12.018 . hal-01266717

\section{HAL Id: hal-01266717 https://hal.sorbonne-universite.fr/hal-01266717}

Submitted on 3 Feb 2016

HAL is a multi-disciplinary open access archive for the deposit and dissemination of scientific research documents, whether they are published or not. The documents may come from teaching and research institutions in France or abroad, or from public or private research centers.
L'archive ouverte pluridisciplinaire HAL, est destinée au dépôt et à la diffusion de documents scientifiques de niveau recherche, publiés ou non, émanant des établissements d'enseignement et de recherche français ou étrangers, des laboratoires publics ou privés. 


\section{Concomitant effects of light and temperature diel variations on the growth} rate and lipid production of Dunaliella salina

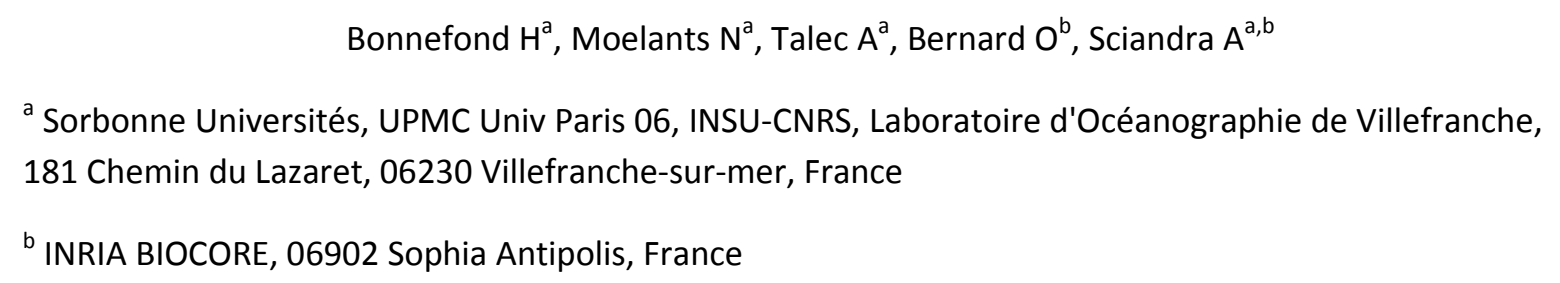

The microalgae Dunaliella salina has the capacity to grow in salterns at high salinity. In this particular shallow environment, $D$. salina is exposed to strong light and temperature variations and has developed various strategies such as cell cycle adaptation and storage of dedicated metabolites. The effects of light/dark cycles have already been studied, but few works focused on the concomitant effects of light and temperature variations characterizing salterns and outdoor conditions. In this study, growth, carbon and nitrogen storage, pigments and lipid production of $D$. Salina was measured, in laboratory conditions mimicking the outdoor light and temperature conditions. A control experiment with constant temperature was carried out with light variations only. During the night, cell respiration was correlated with temperature, following an Arrhenius law. Many differences with the control at constant temperature confirmed that temperature variations are a crucial parameter in outdoor conditions and should be taken into account to predict growth. Triglycerides and pigments production was tightly linked to the light dark cycle.

\section{Introduction}

Microalgae have developed numerous mechanisms to permanently adapt to a fluctuating environment. Key points for survival in periodic conditions are cell cycle synchronization with 
light and temperature [1]. The first consequence of this adaptation is the modulation of carbon and nitrogen acquisition during the cell cycle [2]. The second comprises daily dynamics of storage metabolites like lipids, $[3,4]$. The green microalgae $D$. salina grows in salt lakes or in shallow salterns and tolerates wide ranges of salinity, between $0.5 \mathrm{M}$ to $5 \mathrm{M}$ [5]. Due to low water depth, this species has adapted its metabolism and cell cycle to high temperature and light variations over a course of a day. To survive within a changing environment, Dunaliella $s p$ produces different compounds. Carotenoids, such as betacarotene and lutein, are accessory pigments used as photoprotectors. $D$. salina is among the organisms containing the highest concentrations of carotenoids after metabolic stress [6]. This species can also produce triglycerides (TAG) to store energy and carbon to sustain growth during the night. In addition, Dunaliella $s p$ synthesizes glycerol as an osmo-regulator when grown in hypersaline environments [5]. Industrially, this is the third most important microalgae produced in terms of dry weight (1200 t/year) after Arthrospira sp. and Chlorella sp [7]. It is grown mainly for its carotenoids which have strong antioxidant properties that are utilized in the cosmetic and nutritional markets. Its ability to accumulate triglycerides as a potential source of biofuel is also gaining interest.

Photosynthesis is impacted by temperature and light fluctuations. The effect on inorganic carbon acquisition is direct for light, and indirect for temperature, which modulate enzymatic activity. The simultaneous impact of these factors needs to be studied to better understand the daily pattern of carbon acquisition and storage, but also, over a longer time scale, to comprehend its evolution with seasonal variations [8]. Some studies have been carried out with $D$. salina to investigate the individual effects of light or temperature on growth and metabolites $[8,9,5]$, but the effects resulting from their concomitant variations have not yet been studied. Thus the aim of this study was to investigate the effects of 
concomitant realistic evolution of temperature and light on the metabolic response of $D$. salina, mainly in terms of carbon and nitrogen acquisition and pigment and triglyceride content. These experimental results were compared to a control experiment where temperature was kept constant.

One of our key observations is that a periodic temperature evolution, which is rarely experimentally tested, seems to strongly impact cell dynamics. The cyclic effect of temperature also had a positive impact on carbon fixation. 


\section{Materials and methods}

\subsection{Culturing system}

D. salina (CCAP 18/19) was grown in duplicate $5 \mathrm{~L}$, temperature-controlled water-jacketed vessels previously washed with $10 \% \mathrm{HCl}$ and rinsed with milli-Q water and sterile medium. The enrichment medium was prepared in $20 \mathrm{~L}$ tanks (Nalgen) filled with 3 weeks matured natural seawater filtered on $0.1 \mu \mathrm{m}$, and autoclaved at $110^{\circ} \mathrm{C}$ for $20 \mathrm{~min}$. After cooling, $\mathrm{f} / 2$ medium was added [11]. Nitrates were added separately to the end concentration of 400 $\mu \mathrm{M}$. Fresh medium filtered through a $0.22 \mu \mathrm{m}$ sterile filter (SpiralCap, Gelman) was introduced into the continuous cultures with peristaltic pumps (Gilson) at a dilution rate equal to daily growth rate (Tab. 1). After inoculation, the starting cell concentration was about $2 \times 10^{4}$ cell.mL ${ }^{-1}$ and cultures were first grown in batch mode to allow the algal population to increase rapidly. Then, the turbidostat mode was initiated to stabilize the population at $3 \times 10^{5}$ cell.mL ${ }^{-1}$, a concentration sufficiently high to allow accurate biochemical analyses on small volume samples, and sufficiently low to prevent nutrient limitation and light shading. Each day, the dilution rate (D) was checked by weighting with a precision balance the input flow during 2 min and adjusted, when necessary, to maintain a constant daily cell concentration. The $\mathrm{pH}$ was measured every minute and prevented from exceeding

$\mathrm{pH} 8.3$ by computer-controlled micro-addition of $\mathrm{CO}_{2}$ in the bubbling air (see [12]). Homogenous cultures were maintained by gentle magnetic stirring.

\subsection{Light and temperature}

Light was provided by two arrays of six $50 \mathrm{~cm}$ fluorescent tubes (Dulux ${ }^{\circledR}$, 2G11, 55W/12950, lumilux de lux, daylight, OsramSylvania) placed on each side of the vessels. Photosynthetically active radiation (PAR) was measured by a $4 \pi$ spherical collector (QSL-100, 
Biospherical Instruments) placed between or in the two turbidostats to assure that no light limitation occurred. Temperature was controlled and monitored using a temperature control unit (Lauda RE 415G). Light and temperature were recorded every minute.

\subsection{Culture conditions}

A typical meteorological pattern from a meteorological station located in the Laboratory of environmental biotechnology (INRA-LBE Avenue des Etangs F-11100 Narbonne, south of France), was used as a concrete example of daily natural variability impacting the culture in June. The daily change of temperature in the ponds was calculated by the model of [8], based on this meteorological data. The L/D (14L:10D) cycle was approached by a truncated sinus square function. These conditions were applied in the duplicate cultures C1-LT and C2LT (LT, for light and temperature variations), while constant temperature (at the value of $27^{\circ} \mathrm{C}$ ) was applied in the duplicate cultures C3-L and C4-L (L, for light variation only ; Tab. 1 ). The light intensity was determined to reproduce the averaged irradiance in the pond. Using the Beer-Lambert law for light attenuation, the average light intensity was calculated from the light at the surface, as detailed in [13].

$$
I_{\text {av }}=\frac{I_{\text {inc }}}{\ln \left(\frac{I_{\text {inc }}}{I_{\text {out }}}\right)}\left(1-\frac{I_{\text {out }}}{I_{\text {inc }}}\right)
$$

where $I_{\text {inc }}$ is the incident light intensity ( $\mu$ mol quanta. $\mathrm{m}^{-2} \cdot \mathrm{s}^{-1}$ ) impinging the pond, and $I_{\text {out }}$ the light at the bottom of the raceway. We assumed here that $l_{\text {inc }}$ at noon was such that the photosynthesis rate at the bottom of the pond equaled the respiration rate, corresponding to the (optimal) compensation condition defined by [14]. The compensation condition for $D$. 
salina was determined for $I_{\text {out }}=23 \mu \mathrm{mol}$ quanta. $\mathrm{m}^{-2} \cdot \mathrm{s}^{-1}$ [6]. From (1), it followed that, for the maximal incident light intensity in Narbonne, $I_{\text {inc }}$ was $1364 \mu \mathrm{mol}$ quanta. $\mathrm{m}^{-2} . \mathrm{s}^{-1}$ and the averaged light intensity $I_{a v}$ at noon was equal to $I_{\text {inc }} \times 0.22=300 \mu \mathrm{mol}$ quanta. $\mathrm{m}^{-2} \cdot \mathrm{s}^{-1}$. These conditions were obtained by a computer-controlled cultivation device able to maintain long term continuous cultures [12].

\subsection{Cell population}

Cell concentration and size distribution were monitored every two hours by an automated optical particle counter (HIAC - Royco; Pacific Scientific Instruments). The variability between triplicate measurements was routinely lower than $5 \%$. The mean cell diameter of the population was calculated from its size distribution. Due to high frequency acquisition, continuous functions could be fitted to cell density data using Stavitzky Golay filter [15]. The division rate $\mu\left(\mathrm{d}^{-1}\right)$ was then derived according to the following equation.

$$
\mu=\frac{\operatorname{Ln}\left(\frac{n_{2}}{n_{1}}\right)}{t_{2}-t_{1}}+D
$$

where $n_{1}$ and $n_{2}$ are the cell concentrations (cell.ml ${ }^{-1}$ ) at time $t_{1}$ and $t_{2}$, respectively, and $D$ the dilution rate $\left(d^{-1}\right)$.

\subsection{Nutrient analysis}

Sampling for biochemical analyses were started after a culture-preconditioning period of 15 days, necessary for biomass stabilization and physiological adaptation of cultures to the experimental conditions, and were performed consecutively during 48 hours. Nitrates $\left(\mathrm{NO}_{3}{ }^{-}\right)$ and nitrites $\left(\mathrm{NO}_{2}{ }^{-}\right)$concentrations were automatically measured on-line [16] to ensure that the duplicate cultures were never $\mathrm{N}$-limited. For particulate carbon and nitrogen analyses, $13.15 \mathrm{ml}$ of culture were filtered in triplicates every 2 hours onto glass-fiber filters 
(Whatman GF/C) and precombusted at $450^{\circ} \mathrm{C}$ for $12 \mathrm{~h}$. Samples were kept at $60^{\circ} \mathrm{C}$ until analyses were performed with a CHN analyzer (2400 Series II CHNS/O, Perkin Elmer). The variability between triplicate measurements was routinely lower than $6 \%$. Continuous functions of Stavitzky Golay filter were fitted to discrete data of nitrogen and carbon concentrations $\left(\mu \mathrm{g} \cdot \mathrm{mL}^{-1}\right)$. This allows the computation of the net carbon specific fixation rates of $\mathrm{N}$ and $\mathrm{C}$, respectively $\rho_{\mathrm{N}}$ and $\rho_{C}\left(\mu \mathrm{g} \cdot \mu \mathrm{gC}^{-1} \cdot \mathrm{d}^{-1}\right)$ according to the following equation:

$$
\rho_{N}=\frac{1}{[C]_{t_{2}}}\left(\frac{[N]_{t_{2}}-[\mathrm{N}]_{t_{1}}}{\left(t_{2}-t_{1}\right)}+D \cdot[\mathrm{N}]_{t_{2}}\right)
$$

where $[\mathrm{N}]$ is the particulate nitrogen concentration $\left(\mu \mathrm{g} \cdot \mathrm{mL}^{-1}\right)$ at time $t_{1}$ and $t_{2}$, respectively. The computation of $\rho_{C}$ was done similarly using particulate carbon [C] $\left(\mu \mathrm{g} \cdot \mathrm{mL}^{-1}\right)$.

\subsection{Cellular content analysis}

Lipid analysis protocol was derived from the Bligh and Dyer's method [17]. $200 \mathrm{ml}$ of culture was centrifuged (JOUAN G 412) for $10 \mathrm{~min}$ at $2000 \mathrm{rpm}$, and the pellet was stored at $-80^{\circ} \mathrm{C}$ before lipid extraction. Two successive extractions were performed in a monophasic mixture of chloroform:methanol:salt water (1:2:0.8 v/v). Chloroform and water were then added for phase separation (2:2:1.8 v/v). Chloroform phase was evaporated and total lipids (TL) were stored at $-80^{\circ} \mathrm{C}$ under nitrogen atmosphere to avoid oxidation. Lipid class determination was performed in triplicate after a separation step. A known mass of lipid was spotted (SES A4100 Autospotter) into silica coat rods (Chromarod-SIII), then bathed with 2 successive solvent mixes of hexane: benzene: formic acid (80:20:1) for 24 min and hexane: diethylether: formic acid (97:3:1.5) for 23 min. Following, a drying step ( $5 \mathrm{~min}$ at $110^{\circ} \mathrm{C}$ ),lipid class determination was performed with a latroscan (latroscan New MK 5 from latron, softwear : Chromstar from SES Analysesystem) [18]. The variability between triplicate measurements of 
triglycerides was routinely lower than $20 \%$ (due to very small amount of triglyceride) and less than $3 \%$ for polar lipid.

In the C1-LT culture, cell chlorophylls and carotenoids were sampled every 4 hours. Once extracted in $100 \%$ methanol (containing Vitamin E acetate as internal standard) for 2 hours, cells were disrupted by sonication and clarified by filtration (GF/F Whatman). Analysis was carried out by HPLC (Agilent Technologies 1200) immediately after clarification. For C3-L and

C4-L, $6.54 \mathrm{ml}$ of culture were filtered in triplicates every 2 hours onto glass-fiber filters (Whatman GF/C) precombusted at $450^{\circ} \mathrm{C}$ for $12 \mathrm{~h}$. Samples were kept at $-80^{\circ} \mathrm{C}$ until analyses.

Filters were extracted in acetone $(3 \mathrm{ml})$ for 1 hour at $4^{\circ} \mathrm{C}$ in the dark, with frequent and gentle stirring. After 5 min of centrifugation (JOUAN G 412) at $2000 \mathrm{rpm}$, supernatant was analyzed with a spectrophotometer (Perkin Elmer UV/Vis Spectrophotometer Lambda2).

Chlorophyll a, b and total carotenoids concentrations were determined reading absorbance at 470.0, 644.8 and $661.6 \mathrm{~nm}$ and resolving the system described by Lichtenthaler [19] using pure acetone. The variability between triplicates was lower than $7 \%$.

\subsection{Statistical analysis}

Standard deviation was calculated using physical duplicates of the bioreactors (C1-LT, C2-LT and C3-L, C4-L). The two successive periods of 24 hours where superimposed. Finally, the presented points over 24 hours are the average over the two cycles and the duplicate reactors. The hypothesis of linear correlation was accepted considering a p-value $>0.05$. 


\section{Results}

3.1. Light and temperature variations. Fig. 1 presents the variations of light and temperature in this experiment. It was noticeable that diel variations of temperature were able to reach high amplitudes, ranging from 24 to $33^{\circ} \mathrm{C}$. The maximum of temperature $\left(33^{\circ} \mathrm{C}\right)$ occurred at the end of the light period, whereas the minimum was reached at the end of the dark period. Contrary to the light regime, temperature variation was not symmetrical as it increased faster than it decreased.

\begin{tabular}{|c|c|c|c|c|}
\hline & \multicolumn{2}{|c|}{ C-LT } & \multicolumn{2}{|c|}{$C-L$} \\
\hline & C1-LT & C2-LT & C3-L & C4-L \\
\hline $\begin{array}{l}\text { Maximum light intensity } \\
(\mu \mathrm{mol} . \mathrm{m}-2 . \mathrm{s}-1)\end{array}$ & 278 & 289 & 297 & 273 \\
\hline Light pattern & \multicolumn{4}{|c|}{ Sinus square function $14 \mathrm{~L}: 10 \mathrm{D}$} \\
\hline Temperature $\left({ }^{\circ} \mathrm{C}\right)$ & \multicolumn{2}{|c|}{$\begin{array}{l}\text { Periodic variations } \\
\left(24.4^{\circ} \mathrm{C}-32.9^{\circ} \mathrm{C}\right)\end{array}$} & \multicolumn{2}{|c|}{ Constant $\left(27^{\circ} \mathrm{C}\right)$} \\
\hline Dilution rate $(d-1)$ & 0.69 & 0.70 & 0.42 & 0.45 \\
\hline $\begin{array}{l}\text { Average cell concentration } \\
\text { (cell/L) }\end{array}$ & $2.01 \times 10^{8}$ & $2.24 \times 10^{8}$ & $2.20 \times 10^{8}$ & $2.51 \times 10^{8}$ \\
\hline
\end{tabular}

Table 1 : Experimental conditions applied to the different continuous cultures.

\subsection{Cell number and diameter}

Cell division in C-LT as in C-L cultures occurred preferentially during the dark period with a major event of cell division at the end of the dark period (Fig. 2A). This shows that populations were partially synchronized by the light cycles. In C-LT, cell number increased during the dark period by $32 \pm 4.7 \%$. Cell diameter increased quickly during the light period in C-LT, reflecting the important somatic growth induced by carbon photosynthetic fixation. It decreased more slowly during the dark period, reflecting both carbon respiration and cell division. Cell diameters increased only several hours after the onset of the light period, as 
cell division was still active during this time. Average cell diameter was significantly higher for C-LT $(9.62 \pm 0.01 \mu \mathrm{m})$ than for C-L $(8.54 \pm 0.01 \mu \mathrm{m}$; Fig. $2 \mathrm{~B})$.

\section{3. $C$ and $\mathbf{N}$ fixation}

The daily-averaged carbon fixation rate $\left(\rho_{\mathrm{C}}\right)$ in C-LT was $0.66 \pm 0.036 \mu \mathrm{gC} \cdot \mu \mathrm{gC}^{-1} \cdot \mathrm{d}^{-1} \cdot \rho_{\mathrm{C}}$ values were lower in C-L, $0.53 \pm 0.048 \mu g C . \mu g C^{-1} . d^{-1}$ in accordance with lower division rate. In the CLT cultures, $\rho_{C}$ was strongly correlated with the light intensity $\left(R^{2}>0.99, p\right.$-value $>0.01, n>$ 20) with a maximum value observed just before noon, leading to a significant increase of cell $C$ during the light period. The same trend was observed in $C$-L cultures $\left(R^{2}>0.95, p\right.$-value $>$ 0.01, $\mathrm{n}>20$; Fig. $3 \mathrm{~A}$; Fig. $3 \mathrm{C}$; Fig. 6). At the end of the dark period, the respiration was responsible for C loss averaging $14.5 \pm 2.9 \%$ and $12.9 \pm 0.48 \%$ of the carbon accumulated during the previous $14 \mathrm{~h}$ light phase, respectively in the C-LT and C-L cultures. Nitrogen fixation rate $\rho_{\mathrm{N}}$ was between five and tenfold lower than carbon fixation rate in all experiments (Table 2). In the C-LT cultures, nitrogen fixation also presented a diel cycle, leading to a significant increase of cell nitrogen during the light period (Table 2), but in contrast to carbon, significant fixation rates were also observed during the dark period (Fig. 3B). For the C-L cultures, nitrogen fixation rate followed approximately the same trend but with much lower rates (Fig. 3D).

\begin{tabular}{|l|c|c|c|}
\hline & C1-LT & C2-LT & C4-L \\
\hline Carbon fixation rate $\left(\mu \mathrm{gC} . \mu \mathrm{gC}^{-1} . \mathrm{d}^{-1}\right)$ & $\mathrm{C}-\mathrm{LT}$ & $0.53 \pm 0.048$ \\
\hline Nitrogen fixation rate $\left(\mu \mathrm{gN} . \mu \mathrm{gC}^{-1} . \mathrm{d}^{-1}\right)$ & $0.66 \pm 0.036$ & $0.069 \pm 0.012$ \\
\hline Min cell carbon quota $\left(\mu \mathrm{gC} . \mathrm{cell}^{-1}\right)$ & $0.094 \pm 0.010$ & $9.34 \pm 0.48 \times 10^{-5}$ \\
\hline Max cell carbon quota $\left(\mu \mathrm{gC} . \mathrm{cell}^{-1}\right)$ & $8.89 \pm 0.62 \times 10^{-5}$ & $1.76 \pm 0.13 \times 10^{-4}$ \\
\hline Min cell nitrogen quota $\left(\mu \mathrm{gN} . \mathrm{cell}^{-1}\right)$ & $1.49 \pm 0.2 \times 10^{-4}$ & $1.4 \pm 0.08 \times 10^{-5}$ \\
\hline
\end{tabular}




\begin{tabular}{|c|c|c|c|c|}
\hline Max cell nitrogen quota ( $\mu$ gN.cell ${ }^{-1}$ ) & \multicolumn{2}{|c|}{$2.11 \times 10^{-5} \pm 0.22 \times 10^{-5}$} & \multicolumn{2}{|c|}{$2.36 \pm 0.17 \times 10^{-5}$} \\
\hline $\mathrm{N}$ dark period fixation (\%) on $24 \mathrm{~h}$ & \multicolumn{2}{|c|}{$19.0 \pm 2.54$} & \multicolumn{2}{|c|}{$25.0 \pm 1.17$} \\
\hline $\begin{array}{l}\text { C dark period losses (\%) on the previous } \\
14 \mathrm{~h} \text { of light period }\end{array}$ & \multicolumn{2}{|c|}{$14.5 \pm 2.9$} & \multicolumn{2}{|c|}{$12.9 \pm 0.48$} \\
\hline 24h C fixation ( $\mu g C . \mu g C^{-1}$ ) & \multicolumn{2}{|c|}{$0.66 \pm 0.031$} & \multicolumn{2}{|c|}{$0.43 \pm 0.0099$} \\
\hline $14 \mathrm{~h}$ light period $\mathrm{C}$ fixation ( $\mu \mathrm{gC} \cdot \mu \mathrm{gC}^{-1}$ ) & \multicolumn{2}{|c|}{$0.76 \pm 0.043$} & \multicolumn{2}{|c|}{$0.51 \pm 0.025$} \\
\hline 10h dark period $\mathrm{C}$ fixation $\left(\mu \mathrm{gC} . \mu g \mathrm{C}^{-1}\right)$ & \multicolumn{2}{|c|}{$-0.10 \pm 0.028$} & \multicolumn{2}{|c|}{$-0.06 \pm 0.018$} \\
\hline Max TAG quota ( $\left.\mu \mathrm{g} \cdot \mu g \mathrm{C}^{-1}\right)$ & $1.8 \pm 0.013 \times 10^{-2}$ & $\begin{array}{c}8.7 \times 10^{-3} \pm 1.8 \\
\times 10^{-3}\end{array}$ & NA & NA \\
\hline Min TAG quota ( $\mu \mathrm{g} \cdot \mu \mathrm{gC}^{-1}$ ) & $5.5 \pm 1.0 \times 10^{-3}$ & $3.21 \pm 0.34 \times 10^{-3}$ & NA & NA \\
\hline Max carotenoids quota $\left(\mu \mathrm{g} \cdot \mu g \mathrm{C}^{-1}\right)$ & $4.52 \pm 0.23 \times 10^{-3}$ & NA & NA & NA \\
\hline Min carotenoids quota $\left(\mu \mathrm{g} \cdot \mu \mathrm{gC}^{-1}\right)$ & $2.96 \pm 0.048 \times 10^{-3}$ & NA & NA & NA \\
\hline
\end{tabular}

Table 2 : evolution of the different rates cell quotas ( \pm standard deviation).

\subsection{Chlorophylls and carotenoids.}

The pigments to carbon ratio (Fig. 4 A, B) increased during the dark period and decreased sharply at the beginning of the light period. During the dark period, the amount of pigments per cell did not change significantly until cell division induced significant reduction (data not shown). In all experiments, the Carotenoids: Chlorophyll ratio reached its maximum value a few hours after the light maximum (Fig. 4 C).

\subsection{Lipid response in C-LT cultures}

Total lipids represented about $32 \pm 4.8 \%$ of the cell carbon. In C-LT, the main lipid class was polar lipids. They represented $85 \pm 3.3 \%$, of total lipids, and were constitutive of cell membranes (phospholipids, glycolipids, galactolipids...). B-carotene and triglycerides contributed for $5 \pm 3 \%$ and $3 \pm 1 \%$ of total lipids, respectively. This distribution was conserved during the L/D cycle. The polar lipids: carbon ratio showed small diel variations $( \pm$ 
$13 \%)$ in response to the L/D regime, but the variations were much more marked for the

212

triglycerides ( \pm 36\%; Fig. 5). Triglyceride concentrations increased throughout the light period reaching a maximum at the beginning of the dark period, and then decreased during the dark period (Table 2). Triglycerides by carbon unit were higher in C1-LT than in C2-LT.

\section{Discussion}

\subsection{Responses of nitrogen and carbon quotas to light and temperature}

In all experimental conditions, the specific carbon fixation rate $\rho_{C}$ was tightly linked with the photon flux density (PFD), and the maximum fixation rate coincided with the light peak (Fig 3A, 3C). The linear relationship between $\rho_{C}$ and PFD suggests that the light level applied to the cultures was neither saturating nor photo-inhibiting (Fig. 6). In contrast, nitrogen fixation rate $\rho_{N}$ was much less correlated with PFD, even if higher rates were observed during the light period (Fig 3C, 3D). This reflects the fact that, in non-limited cultures, nitrogen fixation is principally controlled by both the energetic status and the cell cycle [2]. In the current experiments, the decrease in nitrogen fixation during the dark phase could be partly explained by the very low level of carbon storage. Since the energy and carbon necessary for dark fixation of nitrogen can also be provided by the respiration of carbohydrates (not measured), it is questionable to attribute the decrease in nocturnal nitrogen fixation to the low level of triglycerides reached during the night, even if this status can potentially contribute to the depression of dark nitrogen fixation. Another not exclusive explanation is that nitrogen fixation is repressed during mitosis just before cell division [2].

The $\mathrm{C}: \mathrm{N}$ ratio in the $\mathrm{CL}-\mathrm{T}$ cultures was maximum at the end of the light period, i.e. when temperature and level of stored lipids were maximal, and nitrogen uptake begins to 
decrease. The $\mathrm{C}: \mathrm{N}$ ratio was not influenced by temperature. There was no difference in the $\mathrm{C}: \mathrm{N}$ ratio between C-LT and C-L across the L/D cycle.

\subsection{Why the growth rate difference between C-LT and C-L?}

Despite the fact that the same light regime was applied to the cultures, the daily net carbon fixation rate was significantly higher in C-LT than in the C-L culture, i.e. by $25 \%$ (Tab. 2). Such a marked difference of carbon fixation rates between 2 sets of cultures where the daily averaged temperature differed by only $1.8^{\circ} \mathrm{C}$ was clearly unexpected. Using the data of [9] for D. Salina and the model of [20], it was shown that, all things being equal, a difference of $1.8^{\circ} \mathrm{C}$ can change the growth rate by about $\pm 10 \%$, which is much less than the $+25 \%$ observed in this study. Our hypothesis to explain this discrepancy may be that the temperature in C-LT cultures was not constant but cycling. Indeed, some authors have shown that periodic light variations increased growth rate when compared with constant conditions [21]. Temperature could act similarly. Towards a better understanding of the underlying phenomena, we examine here if the differences of measured carbon fixation and dark respiration between C-LT and C-L cultures can explain their difference in net carbon fixation.

Firstly, it is worth noting that the difference in $\rho_{C}$ between C-LT and C-L cultures increased when PFD exceeded $100 \mu \mathrm{mol}$ quanta. $\mathrm{m}^{-2} \cdot \mathrm{sec}^{-1}$. The difference was maximum at $300 \mu \mathrm{mol}$ quanta. $\mathrm{m}^{-2} \cdot \mathrm{sec}^{-1}$ (Fig. 6). This also corresponded to higher temperatures in C-LT than in C-L. During this part of the light period, the carbon fixation rate was more stimulated in the C-LT cultures by high temperatures, leading to a $50 \%$ higher total amount of carbon fixed than in C-L (Table2). This suggests that the temperature increase in C-LT during the light period had 
a clear positive synergetic effect on carbon fixation, compared to $C-L$ at this temperature range.

Secondly, the potential difference in respiration for different temperature regimes during the dark period may explain the difference between C-LT and C-L. Under L/D cycle and constant temperature, the dark respiration rate is dependent on both the light phase duration and light intensity, and is also correlated to the incubation temperature by an Arrhenius law [22]. Under dynamic temperature variations, respiration during the dark period was still correlated to the temperature through the same relationship, with a high level of confidence $\left(R^{2}=0.70, p\right.$-value $>0.05, n>20, C-L T$; Fig. 7). This is not surprising as respiration is under the control of enzymes that are tightly controlled by temperature [23]. In C-L cultures, such a relationship could not be revealed, as the temperature was maintained constant at $27^{\circ} \mathrm{C}$. Mean respiration rates were lower in C-L than in C-LT cultures, confirming the fact that under L/D cycles, respiration is related to the temperature experienced during the light period [22].

In conclusion, the higher temperature during the light period in C-LT leads to a higher carbon fixation rate and a higher respiration rate during the dark period than in C-L. The resulting balance of these opposite terms was a higher net C fixation in C-LT.

\subsection{Lipid storage: a consequence of C-N imbalance uptake in C-LT}

In non-limiting conditions, the major lipid class is polar lipids (Fig. 5). In agreement with [3], polar lipids per carbon unit did not significantly change during the L/D cycle, whereas polar lipids per cell showed a marked minimum observed during the major cell division event (dark period). This preponderantly membrane lipid class is related to cell volume that varied during the $L / D$ cycle $\left(R^{2}=0.83, p\right.$-value $\left.<0.01, n=14\right)$. In $C-L T$, the total lipid content was 32 
$\pm 4.8 \mu \mathrm{g} \cdot \mu \mathrm{gC}^{-1}$ on average (representing $17 \%$ in dry weight, calibration curves not shown), in accordance with the data of [24]. The contribution of energetic lipids, mainly triglycerides, represented only $5 \%$ of the total lipid, confirming that under replete nitrogen conditions, triglycerides are not the main form of carbon storage in this strain of Dunaliella. The amount of triglycerides per carbon unit reached a maximum at the end of the light period. This reflects the imbalance between nitrogen and carbon fixations observed during the light period (Tab. 2) where the excess of fixed carbon could be reallocated in $\mathrm{N}$-free molecules like triglycerides. This mechanism similarly drives the lipid accumulation in nitrogen starvation [25]. In this scenario, cells adapt to the diel cycle by using the energy stored during the light period to proceed to division during the dark phase.

\subsection{Pigment evolution across a light dark cycle}

To our knowledge, no data on carotenoids evolution across a L/D cycle has been published for D. salina. In C-LT, the measured concentrations of beta-carotene per carbon unit reached an average value of $0.004 \mu \mathrm{g} \cdot \mu \mathrm{gC}^{-1}$ ( $2 \%$ of the dry weight), that is 10 -fold lower than the measurements of [9] measured at constant light. This unexpected low level cannot be solely explained by the replete nitrogen conditions in our experiment, but is also probably a characteristic of the chosen strain. There was an increase of beta-carotene content per carbon unit during the dark period due to a decrease in carbon by respiration. This corresponded to a specific beta-carotene fixation rate high and constant $\left(0.7 \mu g_{\text {Beta- }}\right.$ Carotene. $\left.\mu g_{\text {Beta-Carotene }} \cdot \mathrm{d}^{-1}\right)$. At the end of the dark period, during cell division, this increase ceased and the pigment content per carbon unit decreased corresponding to a sharp decrease in the specific beta-carotene fixation rate until the value of $0.5 \mu g_{\text {Beta-Carotene. }} \mu g_{\text {Beta- }}$ Carotene. $\mathrm{d}^{-1}$. The same behavior was observed for all the pigments except zeaxanthin. Beta- 
carotene did not play any role in respiration. Under L/D cycle and nitrogen replete conditions, beta-carotene does not function as carbon storage molecules, in contrast to what happens during nitrogen starvation [26]. Moreover, in synchronized cultures, betacarotene, as the other pigments, was continuously produced by cells except during the cell division event when nitrogen acquisition stopped [2]. The carotenoids:chlorophylls a (car:chla) ratio has been suggested as a possible indicator of stress level $[24,5]$. In previous nitrogen deprivation experiments, with constant light and temperature, a car:chla ratio of 13.2 was reached, whereas for nitrogen replete cultures, a ratio of 0.52 was measured (data not shown). In C-LT, the car:chla ratio evolved between $0.58 \pm 1.23 \times 10^{-2} \mathrm{~g}$ :g at the beginning of the light period to $0.62 \pm 9.13 \times 10^{-3} \mathrm{~g}$ : g, whereas, the evolution was between $0.34 \pm 9 \times 10^{-3}$ g:g and $0.38 \pm 4 \times 10^{-3} \mathrm{~g}: \mathrm{g}$ g/g in C-L (Fig. 4). These low ratios confirmed the absence of photolimitation in this experiment. The increase of this ratio was concomitant with light and reached its maximum a few hours after the light maximum. The temperature evolution did not seem to have impacted this ratio but the sampling frequency was probably too low to observe significant differences.

\section{Conclusion}

This study highlights the growth dynamics of $D$. salina under diel fluctuations of light and temperature, and provides some insights towards understanding the growth dynamics under realistic outdoor conditions. In particular, the importance of temperature variations on cell metabolism is highlighted, suggesting that this parameter should be more often taken into account in addition to light in experimental studies. Additional realistic experiments should support modeling attempts, since, to date, there is no reliable model able to predict algae 


\section{Acknowledgements:}

H. Bonnefond acknowledges the support of an ADEME grant. The experiments were carried

Rémond for her kind help during sampling and Q. Béchet for his intellectual honesty.

\section{References cited}

[1] J. Spudich, R. Sager, Regulation of the Chlamydomonas cell cycle by light and dark., J. Cell Biol. 85 (1980). http://jcb.rupress.org/content/85/1/136.abstract (accessed December 29, 2014).

[2] C. Mocquet, A. Sciandra, A. Talec, O. Bernard, Cell cycle implication on nitrogen acquisition and synchronization in Thalassiosira weissflogii (Bacillariophyceae), J. Phycol. 49 (2013) 371-380. doi:10.1111/jpy.12045.

[3] T. Lacour, A. Sciandra, A. Talec, P. Mayzaud, O. Bernard, Diel Variations of Carbohydrates and Neutral Lipids in Nitrogen-Sufficient and Nitrogen-Starved Cyclostat Cultures of Isochrysis Sp.1, J. Phycol. (2012) no-no. doi:10.1111/j.1529-8817.2012.01177.x.

[4] A. Sukenik, Y. Carmeli, Lipids synthesis and fatty acid composition in Nannochloropsis sp. (EUSTIGMATOPHYCEAE) grown in a light dark cycle, J. Phycol. 26 (1990) 463-469.

[5] H. Chen, J.-G. Jiang, G.-H. Wu, Effects of salinity changes on the growth of Dunaliella salina and its isozyme activities of glycerol-3-phosphate dehydrogenase., J. Agric. Food Chem. 57 (2009) 6178-82. doi:10.1021/jf900447r.

[6] a Ben-Amotz, M. Avron, On the Factors Which Determine Massive beta-Carotene Accumulation in the Halotolerant Alga Dunaliella bardawil., Plant Physiol. 72 (1983) 593-7.

http://www.pubmedcentral.nih.gov/articlerender.fcgi?artid=1066285\&tool=pmcentrez\&rendertype=a bstract.

[7] P. Spolaore, C. Joannis-Cassan, E. Duran, A. Isambert, Commercial applications of microalgae., J. Biosci. Bioeng. 101 (2006) 87-96. doi:10.1263/jbb.101.87.

[8] Q. Béchet, A. Shilton, J.B.K. Park, R.J. Craggs, B. Guieysse, Universal Temperature Model for Shallow Algal Ponds Provides Improved Accuracy, Environ. Sci. Technol. 45 (2011) 3702-9. doi:10.1021/es1040706.

[9] F. García, Y. Freile-Pelegrín, D. Robledo, Physiological characterization of Dunaliella sp. (Chlorophyta, Volvocales) from Yucatan, Mexico., Bioresour. Technol. 98 (2007) 1359-65. doi:10.1016/j.biortech.2006.05.051. 
[10] P.P. Lamers, C.C.W. van de Laak, P.S. Kaasenbrood, J. Lorier, M. Janssen, R.C.H. De Vos, et al., Carotenoid and fatty acid metabolism in light-stressed Dunaliella salina., Biotechnol. Bioeng. 106 (2010) 638-48. doi:10.1002/bit. 22725.

[11] R. Guillard, Culture of phytoplankton for feeding marine invertebrates, Cult. Mar. Invertebr. Anim. Plenum. (1975) 1975.

http://scholar.google.com/scholar?hl=en\&btnG=Search\&q=intitle:Culture+of+phytoplankton+for+feedi ng+marine+invertebrates\#0 (accessed October 3, 2012).

[12] E. Le Floc'h, G. Malara, A. Sciandra, An automatic device for in vivo absorption spectra acquisition and chlorophyll estimation in phytoplankton cultures, (2003) 435-444.

[13] O. Bernard, F. Mairet, Modelling of Microalgae Culture Systems with Applications to Control and Optimization, Adv. Biochem. Eng. (2015).

[14] H. Takache, G. Christophe, J.-F. Cornet, J. Pruvost, Experimental and theoretical assessment of maximum productivities for the microalgae Chlamydomonas reinhardtii in two different geometries of photobioreactors., Biotechnol. Prog. 26 (2010) 431-40. doi:10.1002/btpr.356.

[15] A. Savitzky, M. Golay, Smoothing and differentiation of data by simplified least squares procedures., Anal. Chem. 36 (1964) 1627-1639. http://pubs.acs.org/doi/abs/10.1021/ac60214a047 (accessed October 6, 2014).

[16] O. Bernard, G. Malara, A. Sciandra, The effects of a controlled fluctuating nutrient environment on continuous cultures of phytoplankton monitored by computers, J. Exp. Mar. Bio. Ecol. 197 (1996) 263278. doi:10.1016/0022-0981(95)00161-1.

[17] E. Bligh, W. Dyer, A rapid method of total lipid extraction and purification, Can. J. Biochem. Physiol. 37 (1959) 911-917. http://www.nrcresearchpress.com/doi/abs/10.1139/o59-099 (accessed March 22, 2012).

[18] R. Ackman, Flame ionization detection applied to thin-layer chromatography on coated quartz rods, Methods Enzymol. (1981). http://www.sciencedirect.com/science/article/pii/S0076687981720135 (accessed November 6, 2012).

[19] H. Lichtenthaler, Chlorophylls and carotenoids: Pigments of photosynthetic biomembranes, Methods Enzymol. 148 (1987) 350-382. http://www.sciencedirect.com/science/article/pii/0076687987480361 (accessed March 13, 2012).

[20] O. Bernard, B. Rémond, Validation of a simple model accounting for light and temperature effect on microalgal growth., Bioresour. Technol. 123 (2012) 520-7. doi:10.1016/j.biortech.2012.07.022.

[21] M. V. Nielsen, Irradiance and daylength effects on growth and chemical composition of Gyrodinium aureolum Hulburt in culture, J. Plankton Res. 14 (1992) 811-820. doi:10.1093/plankt/14.6.811.

[22] J. Grobbelaar, C. Soeder, Respiration losses in planktonic green algae cultivated in raceway ponds, J. Plankton Res. 7 (1985) 497-506. http://plankt.oxfordjournals.org/content/7/4/497.short (accessed October 7, 2014).

[23] N. Devos, M. Ingouff, R. Loppes, R.F. Matagne, Rubisco adaptation to low temperatures: a comparative study in psychrophilic and mesophilic unicellular algae, J. Phycol. 34 (1998) 655-660. doi:10.1046/j.1529-8817.1998.340655.x.

[24] M.J. Griffiths, S.T.L. Harrison, Lipid productivity as a key characteristic for choosing algal species for biodiesel production, J. Appl. Phycol. 21 (2009) 493-507. doi:10.1007/s10811-008-9392-7. 
[25] M. Vítová, K. Bišová, S. Kawano, V. Zachleder, Accumulation of energy reserves in algae: From cell cycles to biotechnological applications, Biotechnol. Adv. (2015). doi:10.1016/j.biotechadv.2015.04.012.

[26] P.P. Lamers, M. Janssen, R.C.H. De Vos, R.J. Bino, R.H. Wijffels, Exploring and exploiting carotenoid accumulation in Dunaliella salina for cell-factory applications., Trends Biotechnol. 26 (2008) 631-8. doi:10.1016/j.tibtech.2008.07.002.

[27] E. Young, J. Beardall, Photosynthetic function in Dunaliella tertiolecta (Chlorophyta) during a nitrogen starvation and recovery cycle, J. Phycol. 905 (2003) 897-905.

403 http://onlinelibrary.wiley.com/doi/10.1046/j.1529-8817.2003.03042.x/full (accessed January 30, 2013).

404 


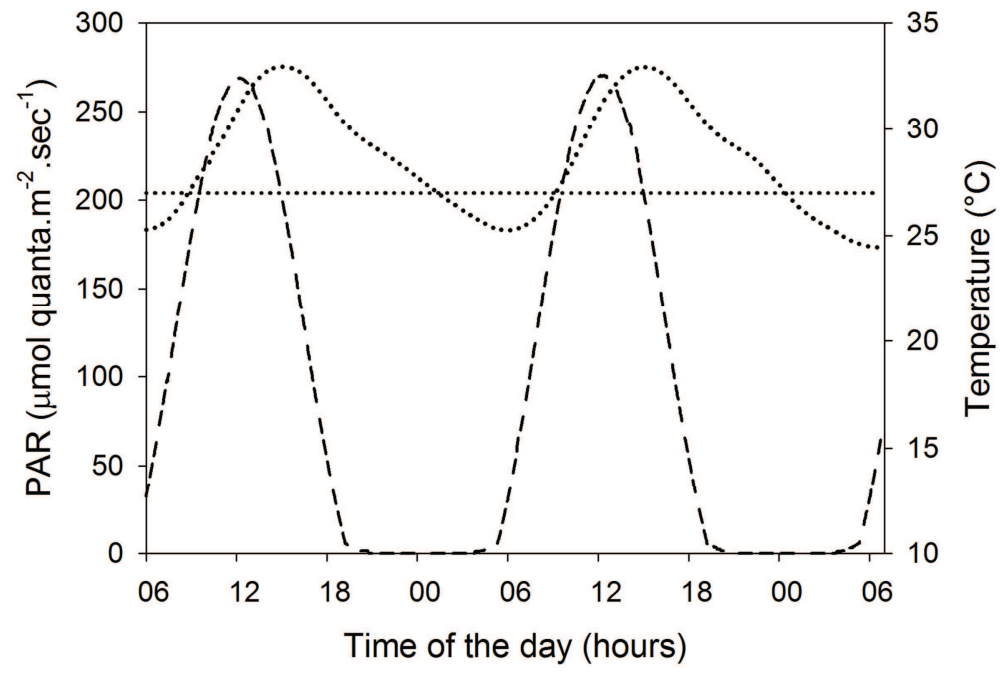

Figure 1. PAR (dashed line) applied to cultures C-LT and C-L. Temperature was maintained constant at $27^{\circ} \mathrm{C}$ in C-L cultures (horizontal dotted line), whereas it varied in C-LT cultures (dotted curve). 

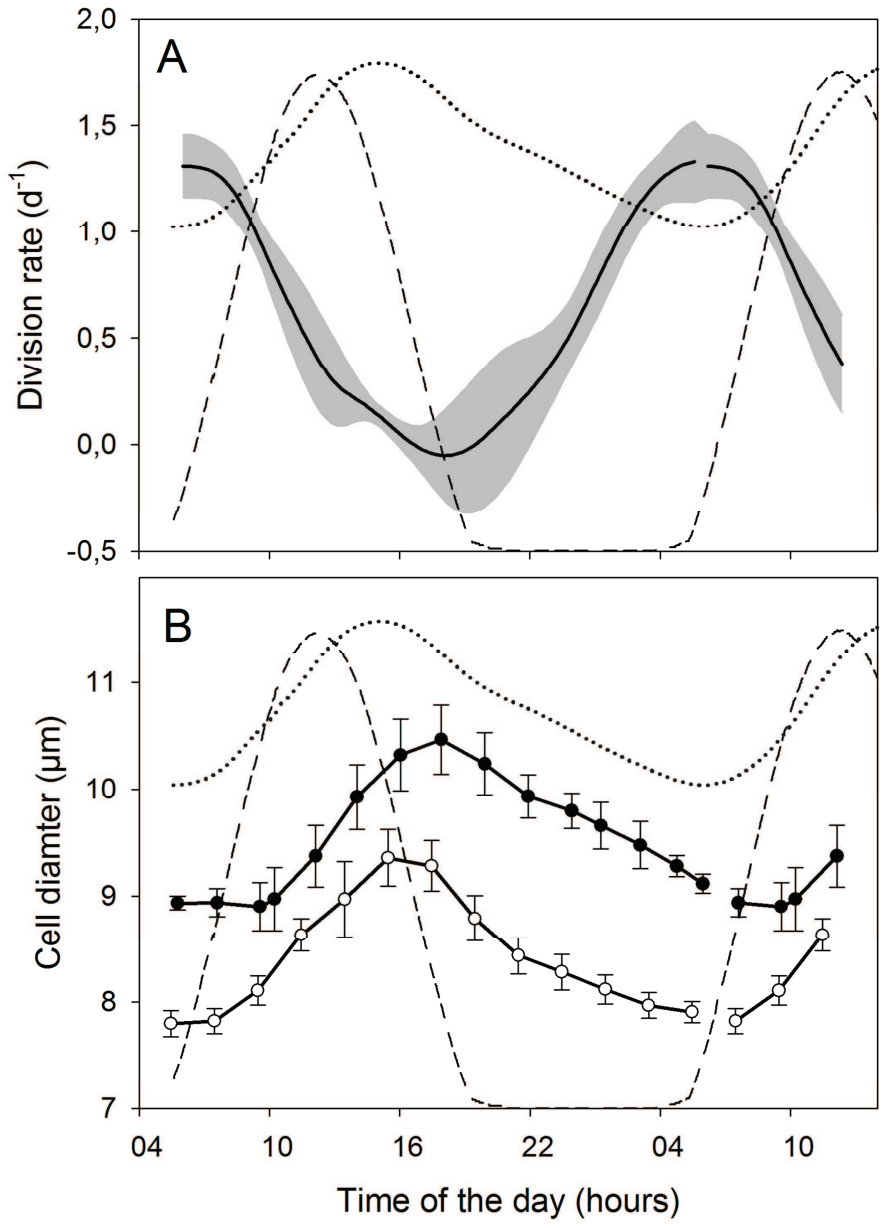

Figure 2. A: mean cell division rate (continuous black line) +/- one SD (grey area) in C-LT cultures. B: mean cell diameter in C-LT (closed symbol) and C-L (open symbol) cultures. Temperature variation (dotted line), light variation (dashed line). 

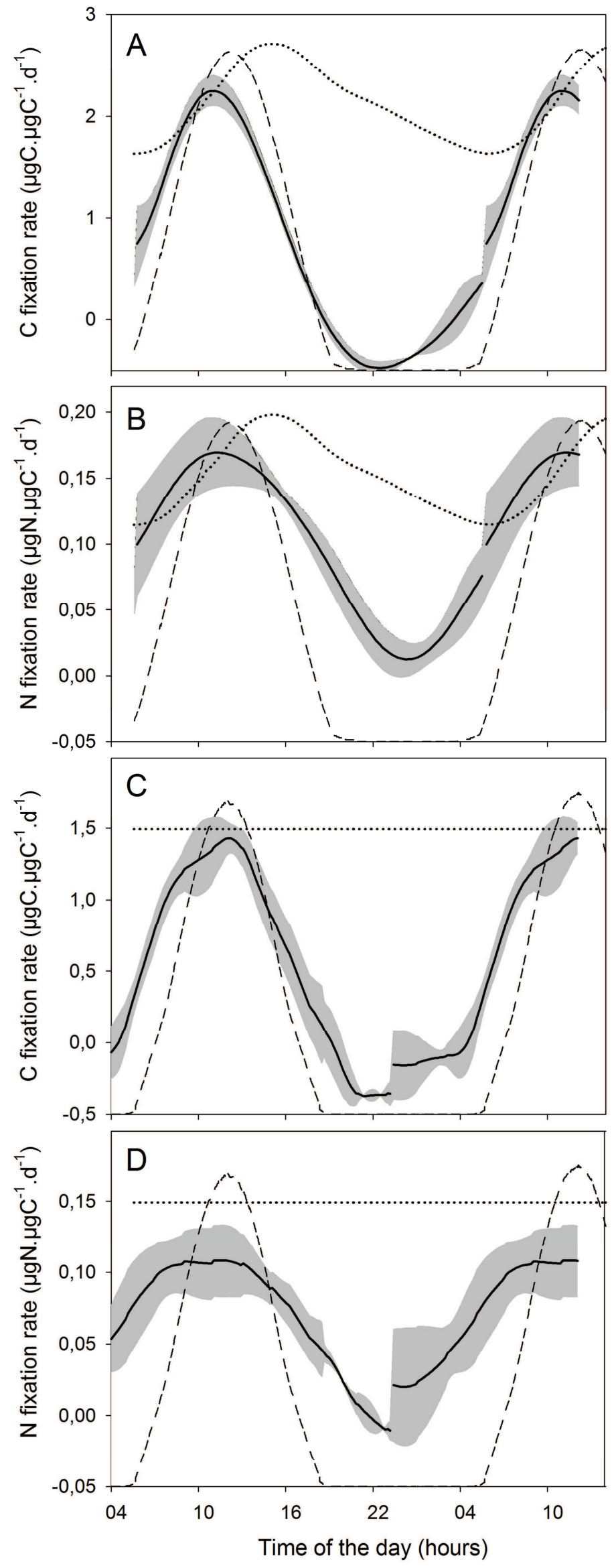

Figure 3. Averaged values of carbon fixation rate in C-LT (A) and C-L (C) cultures, and of nitrogen fixation rates in C-LT (B) and C-L (D) cultures. Temperature variation (dotted line), light variation (dashed line). 


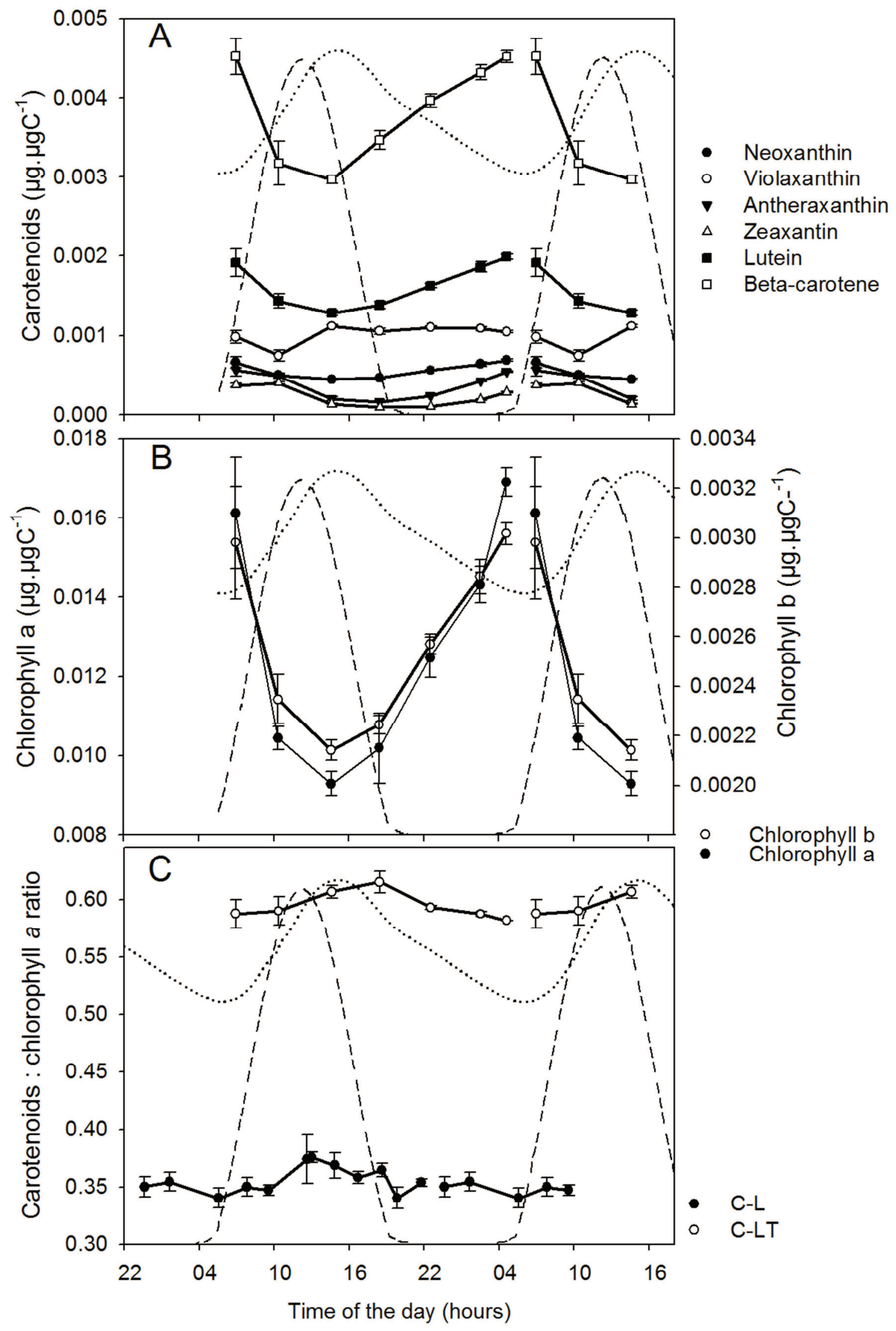

Figure 4. A: quota of xanthophylls and beta-carotene in C-LT cultures. B: quotas of chlorophylls $a$ and $b$ in C-LT cultures. C: carotenoids:chlorophyll $a$ ratio in C-L and C-LT cultures. Temperature variation (dotted line), light variation (dashed line). 


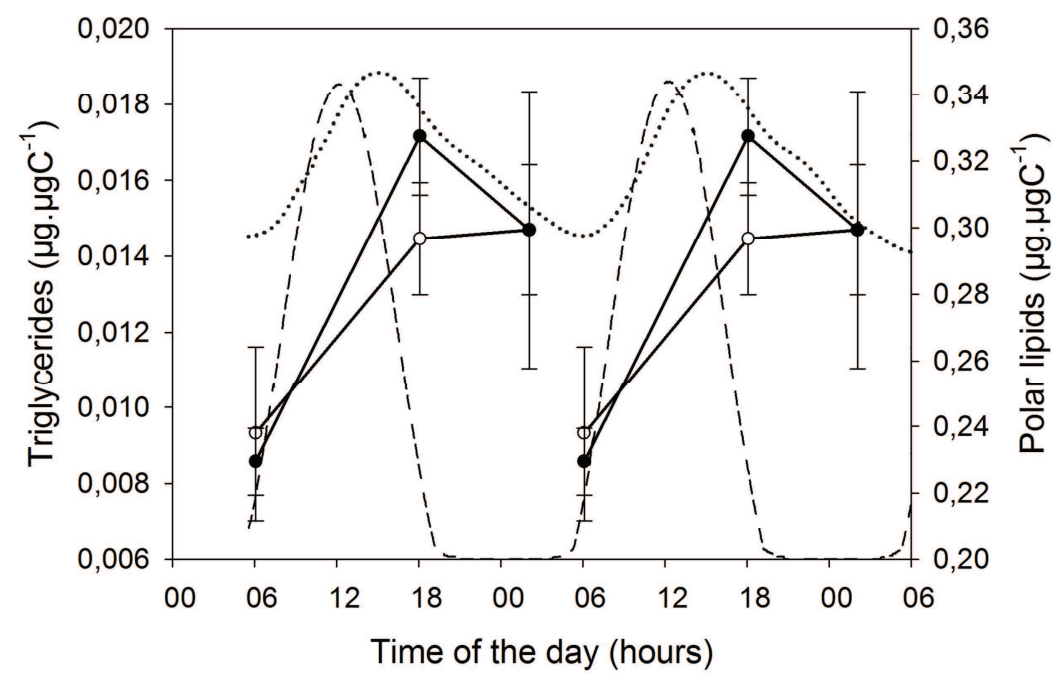

Figure 5. Quotas of polar lipids (open symbol) and triglycerides (closed symbol) in C-LT cultures. Temperature variation (dotted line), light variation (dashed line). 


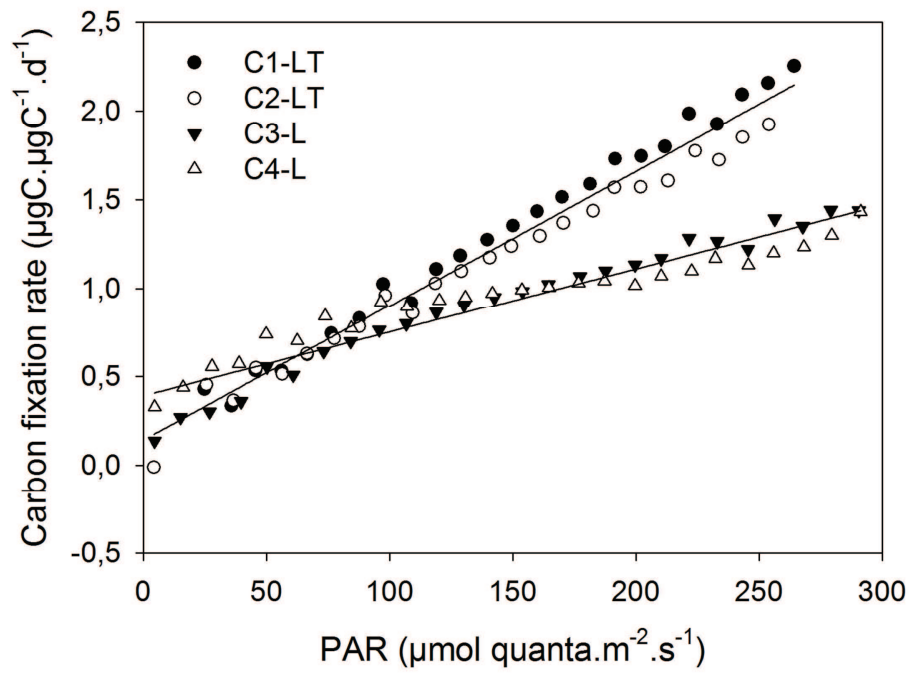

Figure 6. Correlation between the specific carbon fixation rate and PAR in C-LT and C-L cultures.

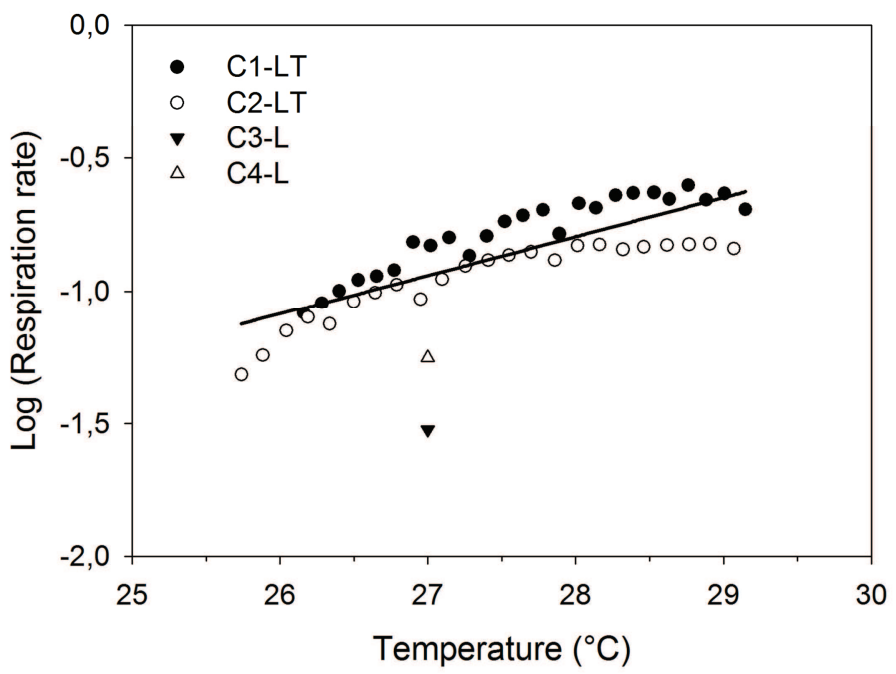

Figure 7. Arrhenius plots of respiration rate measured during the dark period only, in C-LT and C-L cultures. 